\title{
Journal of Exercise Rehabilitation goes beyond
}

\section{Khae-Hawn Kim}

We announce the annual meeting of Korean Society of Exercise Rebabilitation celebrated our tenth birthday this month. To this date, we have covered different genres of translational research, such as exercise neuroscience, rehabilitation program and physical practice, and also written about health promoting lifecycle, revitalization movement, and clinical sport medicine. We have done our best to keep our readers updated on the latest trends in rehabilitation exercise and to also taken an in-depth look in to the cutting edge of the times through popular exercise and scientific works. Simply put, there was nothing we didn't cover at Journal of Exercise Rehabilitation, the official journal of Korean Society of Exercise Rehabilitation.

Our anniversary meeting offers four topics that summarize the hottest trends in global exercise rehabilitation today, "biokinetics, application of therapeutic recreation for brain exercise, molecular mechanism of rehabilitation on neuroplasticity, and adult neurogenesis associated with exercise." We also focused on real practice of exercise and scientific works adopting fresh conceptual approaches on specification and function at the molecular and cellular levels, neural circuits, systems and behavioral levels.

The rehabilitation spawned by real life application is changing our daily life style. We are gradually becoming addicted to seeing the boundaries between creative real application and translational scientific research that are being to blur and transcend.

Editor-in-Chief Department of Urology, Gachon University Gil Medical Center, 21 Namdong-daero 774beon-gil, Namdong-gu, Incheon 405-760, Korea E-mail: kimcho99@gilhospital.com

This is an Open Access article distributed under the terms of the Creative Commons Attribution Non-Commercial License (http://creativecommons.org/licenses/by-nc/3.0/) which permits unrestricted non-commercial use, distribution, and reproduction in any medium, provided the original work is properly cited. 